\title{
The Behavior of Piles Installed in Medium Dense Sand Within MSE Wall System
}

\author{
Salah M. Hamza ${ }^{*}$, Shaymaa T. Kadhim (D), Saad F. A. Al-Wakel \\ Civil Engineering Department, University of Technology,Baghdad,Iraq. \\ *Corresponding author Email: 42368@student.uotechnology.edu.iq
}

\section{H I G H L I G H T S}

- Analyzing laterally-loaded pile with MSE wall system using reduced scale model.

- The lateral resistance of pile increased with an increase of the slenderness ratio.

- The pressure applied on MSE wall decreased with an increase of the pile offset.

\section{A R T I C L E I N F O}

Handling editor: Wasan I. Khalil

\section{Keywords:}

Lateral load

MSE wall (retaining wall)

Pile

$\mathrm{BRC}$ reinforcement

Medium dense sand

\author{
A B S T R A C T
}

\begin{abstract}
Mechanically Stabilized Earth Walls (MSE) were widely used in several essential infrastructures, such as the abutments on a bridge. The need for a support base for a shallow or a deep bridge increased in the MSE wall system. In this research, factors affecting the performance of laterally loaded piles embedded in medium dense sand with a relative density of $50 \%$ behind an MSE wall were studied using lower-scale models in the laboratory. For instance, the effect of pile offset and slenderness ratio on the pile's lateral capacity and pressure on the MSE wall. Three different slenderness ratios were introduced (i.e. L/D of 19.3, 21.7, and 24.1). The results showed a significant increase in pile lateral capacity occurring with the increase in pile offset or slenderness ratio (i.e., L/D). While increasing the pile offset reduced, the pressure on the wall so that the wall's effect will be insignificant when the pile offset reaches a value of $6 \mathrm{D}$.
\end{abstract}

\section{Introduction}

Retaining walls have been frequently used to support soil backfill for road applications [1]. Mechanically Stabilized Earth Walls (MSE) were widely used for bridge abutments and embankments in recent decades. The primary reasons for using this retaining wall instead of concrete walls are cost-effectiveness, good efficiency, and durability. Soil stabilization is the fundamental concept of MSE walls.

French architect, Henri Vidal, in the early 1960s, introduced this idea based on the concept of soil reinforcement to build the first MSE wall. His research had the beginning of the use of strengthening soil in various the earth buildings.

In the United States, more than 8,000 walls have been built. Since the first reinforced retaining wall was built in 1972 on California's State Highway 39 [2]. Additionally, at the same time, 37 countries across the world built 23,000 reinforcing earth structure [2]. The MSE wall system comprises of three essential parts: backfill soil, reinforcement, and wall facing, as shown in Figure 1.

The advantages of MSE walls over traditional retaining walls are summarized as follows [4]:

1) Easiness and quick construction procedures.

2) They do not require large construction equipment or skilled workers.

3) They require less site planning than alternative systems.

4) They require less space in front of the structure.

5) They reduce the acquisition of the right-of-way.

6) They are technically possible to be constructed as high as 100 feet or greater.

7) They may be more resistant than alternative systems in terms of distortions.

During the design process of MSE walls, external and internal stability analyses are evaluated. The external stability of MSE walls assumes the reinforced soil and wall work as one rigid mass under external forces. External failure modes may include sliding, overturning, and bearing. Internal failure for an MSE wall can occur in two ways: reinforcement elongation and pullout. 


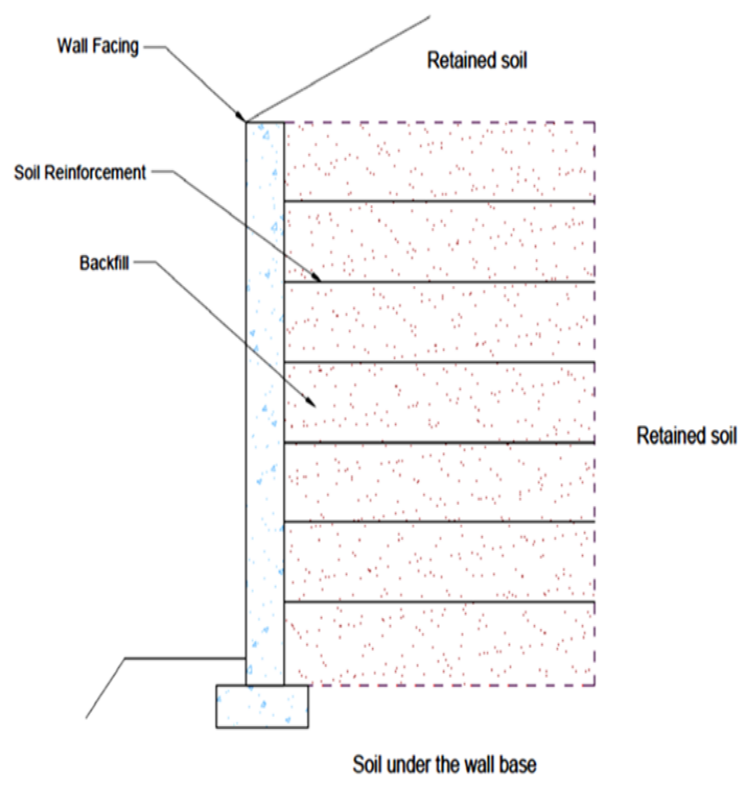

Figure 1: Main parts of MSE wall system [3]

Relatively few full-scale tests were conducted to determine Piles' lateral resistance near MSE walls. Reference [5] a series of full laterally load tests were carried out on 36 in Dia of drilled shafts lined with extensible geogrids behind a 20 -foot block masonry wall at four different distances. Test results revealed that the shaft's lateral resistance spaced two-diameter on the wall was around 50 percent of the resist given by four-diameter spaced shaft behind the wall. Reference [6] performed a full-scale study. 12.75-in diameter piles were tested at three sites reinforced by steel strips behind chicken wire wall panels. The test piles were spaced behind the wall face at $6.3,2.7$, and 1.3 pile diameters. Reference [7] performed a series of a full-scale MSE wall and piles were driven behind the wall at different offsets (i.e. 1.7, 2.8, 3.1, and 3.9 of pile diameter) located behind the wall. The data showed that the pile's lateral resist reduced as the distance from the pile to the wall became closer. Another series of full-scale tests were carried out on $400 \mathrm{~mm}$ diameter the piles located at 1.6, 2.9, and 5.2 of pile diameter behind an MSE wall of $10.5 \mathrm{~m}$ high [8]. Reference [9] concluded that for laterally loaded piles within MSE system, there was a significant decrease in the induced forces in the reinforcement units when the pile is located at farther distance from the wall.

The need for a shallow or deep bridge support base in an MSE wall has increased. Thus, various piles are used, but impact of their position within an MSE wall structure has not been full investigation. The MSE walls do not contain approved pile design procedures or methods. To date, few complete there have been studies. Performed to determine the action of a lateral loaded pile within the MSE system. This study investigates the effect of some factors like the offset pile of the wall and slenderness ratio (i.e., the ratio of pile length to pile diameter (L/D)) on the lateral pile capacity and the pressure on the wall when the pile has a relative density of $50 \%$ embedded in medium dense sand.

\section{Material Used and Testing Program}

\subsection{Soil used}

The soil samples used in this research were taken from the town of Ain Al-Tamr in the province of Karbala. Figure 2 displays the sieve analysis to obtain the grain size distribution according to ASTM (D422-01) requirements [10]. The effective size of soil (D10) is $0.15 \mathrm{~mm}$. The soil is classification as poorly graded sand according to USCS. Maximum and minimum dry unit weights of soil are $18.05 \mathrm{kN} / \mathrm{m} 3$ and $15.82 \mathrm{kN} / \mathrm{m} 3$ in accordance to ASTM D 4253 and ASTM D4254, respectively [11] and [12].

\subsection{Pipe piles}

In this research, a $20.5 \mathrm{~mm}$ diameter steel pipe pile with a $0.3 \mathrm{~mm}$ wall thickness and different lengths of pile (286, 335.5, and 385) $\mathrm{mm}$ are used to simulate different slenderness ratios; (i.e. L/D of 19.3, 21.7, and 24.1), respectively.

\subsection{Blocks of wall facing}

Several concrete blocks are prepared from larger concrete blocks. The dimensions of the block used in the physical models are $380 \mathrm{~mm}$ length, $50 \mathrm{~mm}$ width and $45 \mathrm{~mm}$ height.

\subsection{BRC reinforcement}

Soil reinforcing is an important component of the MSE wall, since it helps to keep it stable. The internal stability of the wall is preserved in this study by punched-down BRC with apertures. The connection between BRC and wall facing is mechanical. BRC is made of iron in the form of a grid of squares, each square with dimensions (10 x 10) $\mathrm{mm}$ and a thickness of $1 \mathrm{~mm}$. 


\subsection{Instrumentations}

Figure 3 illustrates the test setup of the physical models. In order to conduct the experimental work, several instrumentations were used:

1) A test box measuring $830 \mathrm{~mm}$ in height, $1400 \mathrm{~mm}$ in length, and $400 \mathrm{~mm}$ in width.

2) Digital weighing indicator.

3) Load cell.

4) Pressure cells.

5) Dial gauge.

\subsection{Test Setup}

The steps of preparation were generally nearly the same applies to all tests, which includes: firstly, the BRC layers were prepared and placed down to the desired depth locations through the pile offset prepared holes, as shown in Figure3(a). Secondly, a frame of steel section is used for leveling the pile vertically to prepare for the pipe pile installation. The frame was installed at the top of the test box and the pile model is bound at the mid-point of it. The frame contains a cylindrical cavity with a diameter greater than the diameter of the pile by $2 \mathrm{~mm}$ with screws to install the pile during preparing the model. Thirdly, after making sure that the pile model is located vertically at its position, it was constructed the wall by placing the blocks of concrete in rows between the BRC layers at the appropriate spacing. Fourthly, the test box was filled with weighted sand. Then, the BRC layer was placed on the required depths in the sand bed. After that, Attaching the pressure cells to the inside face of the wall was performed. The steps three and four were repeated until the wall reached its full height. The steel bar was then taken from the pile, and the loading system was set up. d. A dial gauge with an accuracy of $0.001 \mathrm{~mm}$ is used to measure the lateral displacement of the pile during the application of lateral loads while the measuring system of the wall stress is presented by pressure sensors. Figure 3(b) shows the specimen is ready for testing.

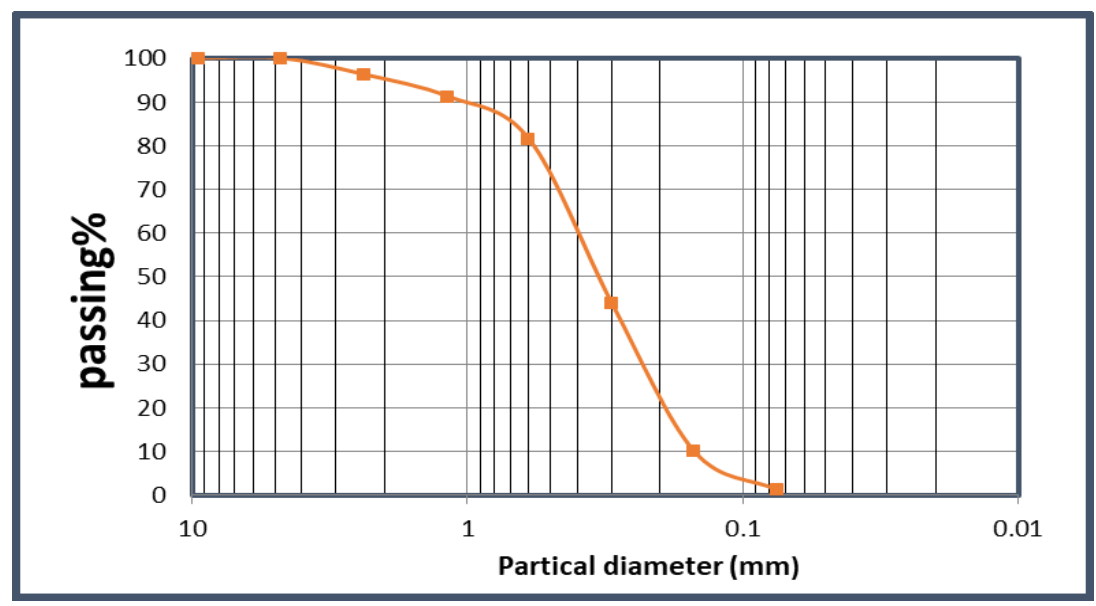

Figure 2: The grains size distribution curve

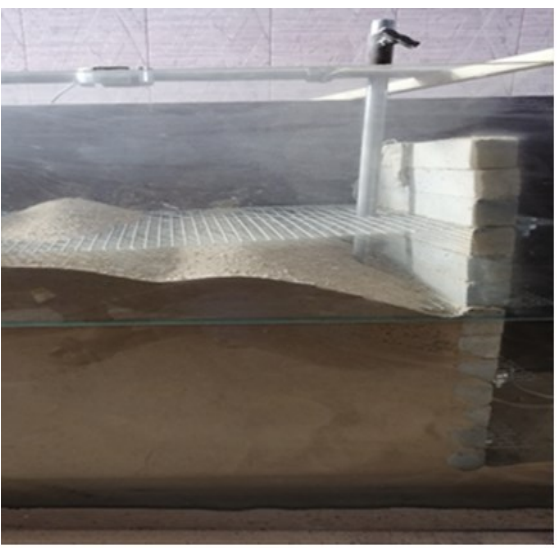

(a)

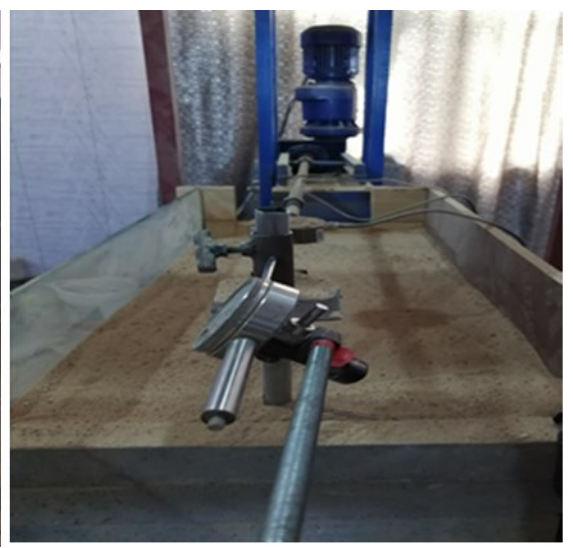

(b)

Figure 3: The test setup of the physical models: (a) The installation of the pile within MSE wall system; and (b) The application of lateral load to the pile

\section{Test Results and Discussion}

Nine models are tested in this paper to study the influence of some factors: slenderness ratio and pile offset (i.e., the distance of pile from the wall facing), on the lateral capacity of the pile and the measured pressure on the wall. The soil (i.e., sand) is compacted to a relative density of 50\%. The height of the MSE wall in the physical models is $450 \mathrm{~mm}$. The length of 
reinforcement and the spacing between BRC layers are kept constant during the experimental work to values of $315 \mathrm{~mm}$ and $90 \mathrm{~mm}$, respectively.

\subsection{Effect of pile offset and slenderness ratio on the pile lateral capacity}

In this paper, three pile offsets are investigated: $2 \mathrm{D}, 4 \mathrm{D}$, and $6 \mathrm{D}$, where (D) the diameter of a pile. The ultimate lateral load capabilities of the piles are calculated using the curves load-displacement. Figure 4(a), (b), and (c) presented the loaddisplacement curves at the offsets pile of $41 \mathrm{~mm}(2 \mathrm{D}), 82 \mathrm{~mm}(4 \mathrm{D})$, and $123 \mathrm{~mm}(6 \mathrm{D})$, respectively. An increase in the pile offset, for the same (L/D), increased the pile's ultimate lateral load capacity. For the purpose of comparison, the ultimate of laterally load for a pile with L/D of 19.3 and pile offset of $6 \mathrm{D}$ increased to $51 \%$ and $24.7 \%$ greater than those for the offsets pile of $2 \mathrm{D}$ and $4 \mathrm{D}$, respectively, at the same L/D. For example, for the same pile offset, $6 \mathrm{Dcapacity}$ of ultimate lateral with an L/D of 24.1 increased to $77.3 \%$ and $25.3 \%$ greater than those with L/D of 19.3 and 21.7 , respectively.

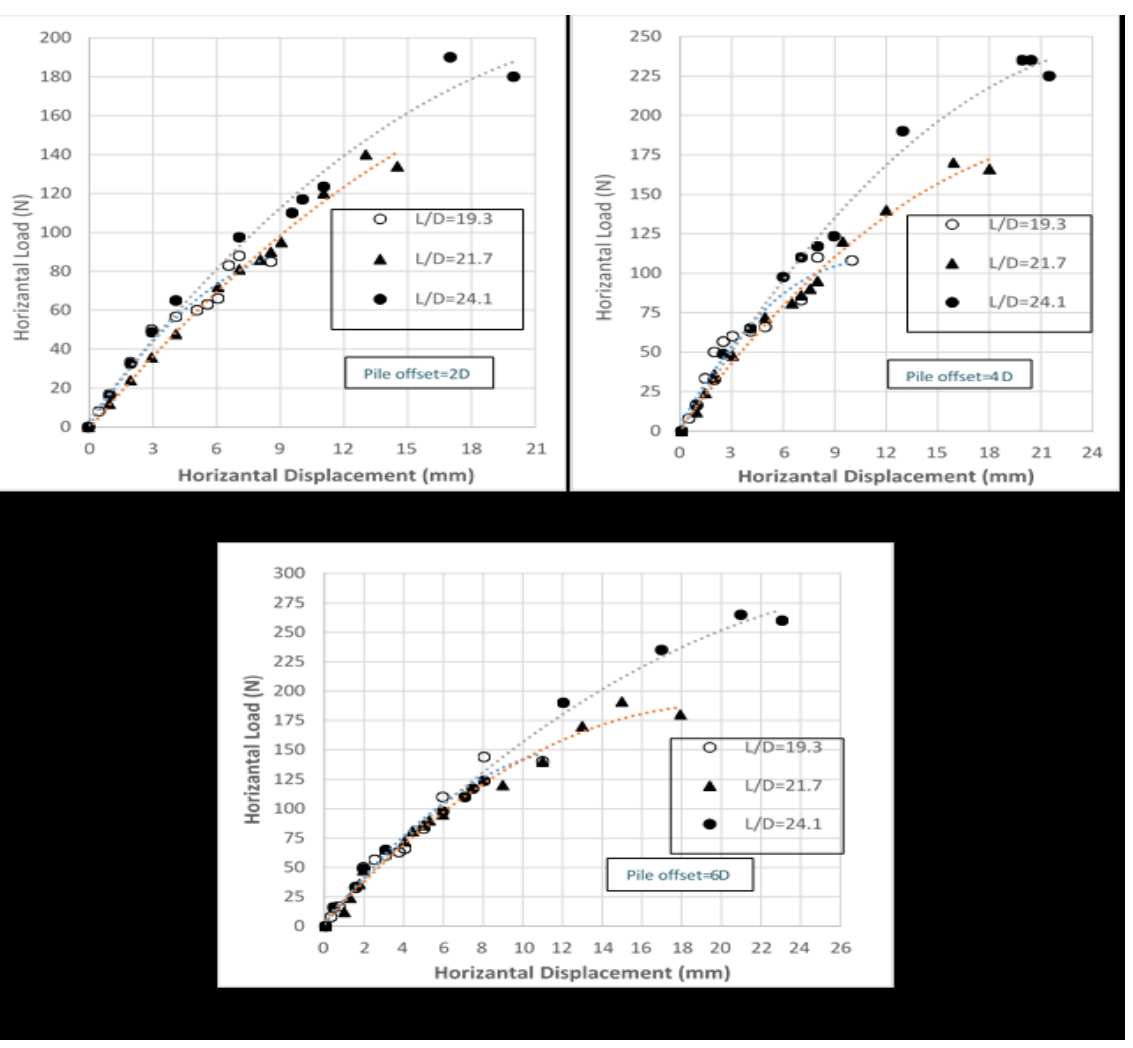

Figure 4: Lateral loads-displacement curve of pile in medium sand with relative density $50 \%$ : (a) pile offset (2D); (b) pile offset (4D); and (b) pile offset (6D)

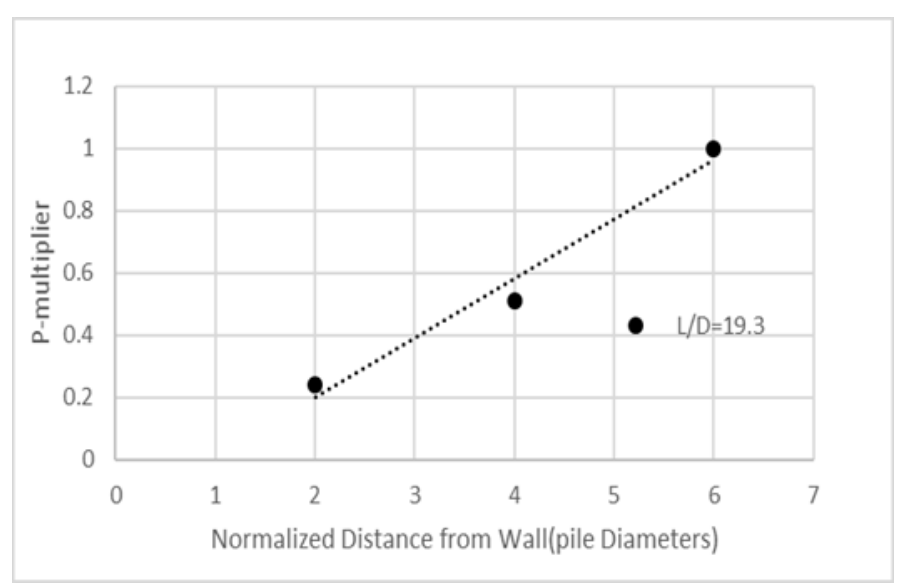

Figure 5: Tentative p-multiplier curve as a function of normalized distance (Nelson, 2013) 


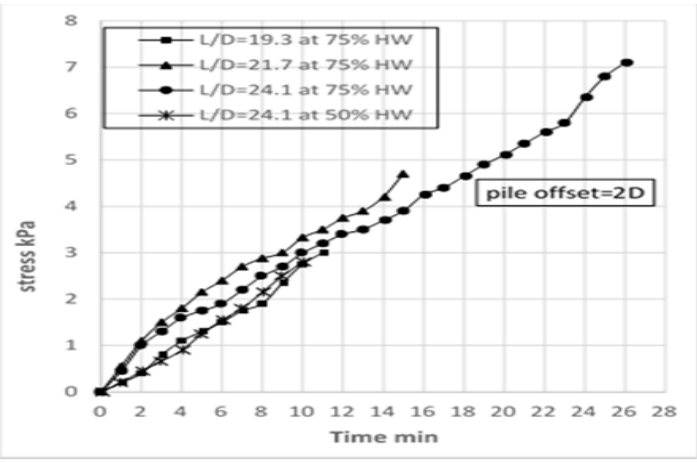

(a)

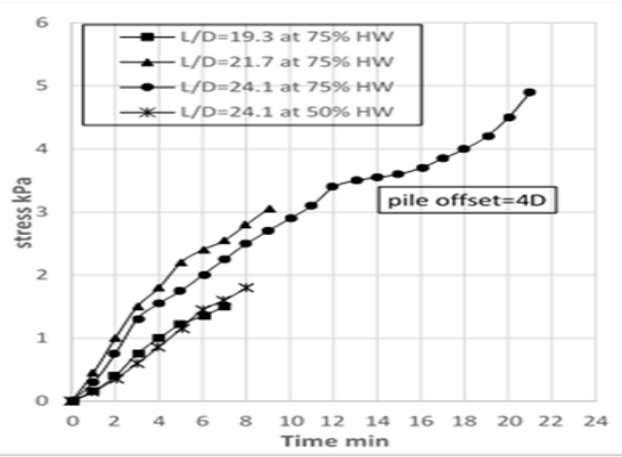

(b)

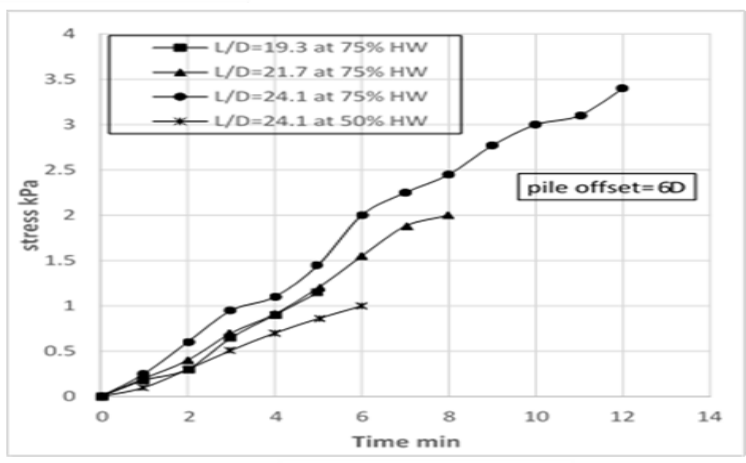

(c)

Figure 6: Stress-time curve of MSE wall in sand with relative density 50\%: (a) pile offset (2D); (b) pile offset (4D); and (c) pile offset (6D)

The results of the present study are used to establish a plot of a p-multiplier versus a normalized distance from the wall (Distance from the middle of the pile to the back of the wall (S) divided by the pile diameter), as shown in Figure 5. If a pile is placed at least 6 pile diameters behind the wall, a p-multiplier of 1 can be used, which indicates that the wall does not affect the pile's lateral resistance.

\subsection{Effect of pile offset and slenderness ratio on the pressure on MSE wall}

The ultimate pressures on MSE wall are determined from the stress-time curves. Figure 6(a), (b), and (c) illustrated the stress-time curves at offsets of pile of $41 \mathrm{~mm}(2 \mathrm{D}), 82 \mathrm{~mm}$ (4D), and $123 \mathrm{~mm}$ (6D), respectively.

The pressure sensors are located at two locations of the wall; at $50 \%$ and $75 \%$ of the height of the wall from the wall base. An increased in offset the pile decreased the pressure on the wall because of the increased distance between the pile and wall that leads to a decrease in the pressure on the wall. While an increase in the L/D increased the pressure on the wall since increased the lateral pile deflection resistance in the soil when $\mathrm{L} / \mathrm{D}$ increased and as a result, the lateral earth pressure increased on the wall. For comparison purposes, the ultimate pressure on the wall for L/D of 19.3 and pile offset of 2D is greater than the pressures on the wall when the offsets pile 4D and 6D, respectively at the same L/D. Furthermore, the wall pressure increased with increasing the slenderness ratio (L/D) for the same the offset pile. There was the pressure high zone that formed at $75 \%$ of the height of the wall. This zone created from resistance of the soil to deflection of the laterally loaded pile. This soil at that location was compressed.

\section{Test Results and Discussion}

Nine models are tested in this paper to study the influence of some factors: slenderness ratio and pile offset (i.e., the distance of pile from the wall facing), on the lateral capacity of the pile and the measured pressure on the wall. The soil (i.e., sand) is compacted to a relative density of 50\%. The height of the MSE wall in the physical models is $450 \mathrm{~mm}$. The length of reinforcement and the spacing between BRC layers are kept constant during the experimental work to values of $315 \mathrm{~mm}$ and $90 \mathrm{~mm}$, respectively.

\subsection{Effect of pile offset and slenderness ratio on the pile lateral capacity}

In this paper, three pile offsets are investigated: 2D, 4D, and 6D, where (D) the diameter of a pile. The ultimate lateral load capabilities of the piles are calculated using the curves load-displacement. Figure 4(a), (b), and (c) presented the loaddisplacement curves at the offsets pile of $41 \mathrm{~mm}(2 \mathrm{D}), 82 \mathrm{~mm}(4 \mathrm{D})$, and $123 \mathrm{~mm}(6 \mathrm{D})$, respectively. An increase in the pile offset, for the same (L/D), increased the pile's ultimate lateral load capacity. For the purpose of comparison, the ultimate of laterally load for a pile with L/D of 19.3 and pile offset of 6D increased to 51\% and 24.7\% greater than those for the offsets pile of $2 \mathrm{D}$ and $4 \mathrm{D}$, respectively, at the same L/D. For example, for the same pile offset, 6Dcapacity of ultimate lateral with an L/D of 24.1 increased to $77.3 \%$ and $25.3 \%$ greater than those with L/D of 19.3 and 21.7 , respectively. 
The results of the present study are used to establish a plot of a p-multiplier versus a normalized distance from the wall (Distance from the middle of the pile to the back of the wall (S) divided by the pile diameter), as shown in Figure 5 . If a pile is placed at least 6 pile diameters behind the wall, a p-multiplier of 1 can be used, which indicates that the wall does not affect the pile's lateral resistance.
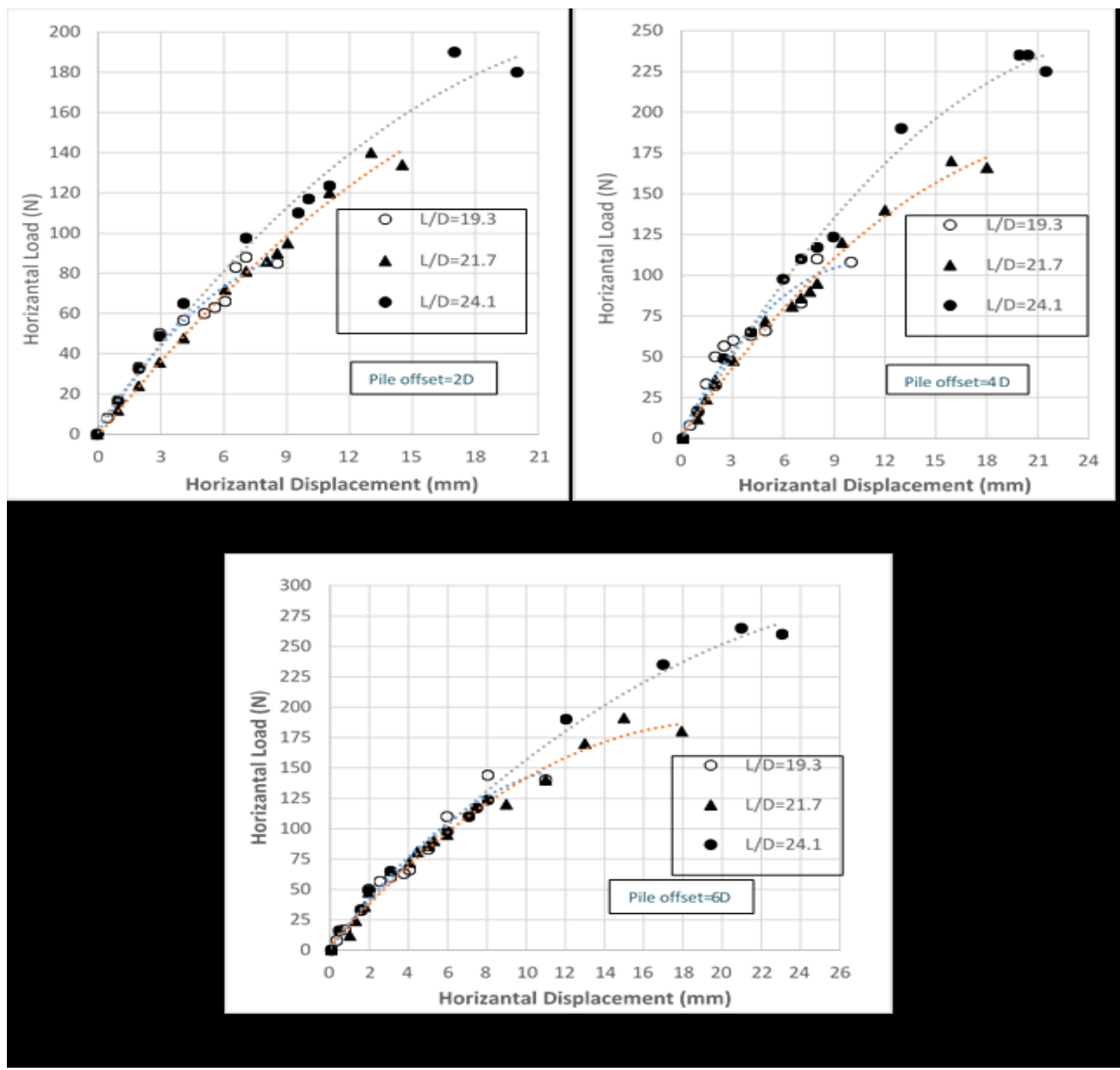

Figure 7: Lateral loads-displacement curve of pile in medium sand with relative density $50 \%$ : (a) pile offset (2D); (b) pile offset (4D); and (b) pile offset (6D)

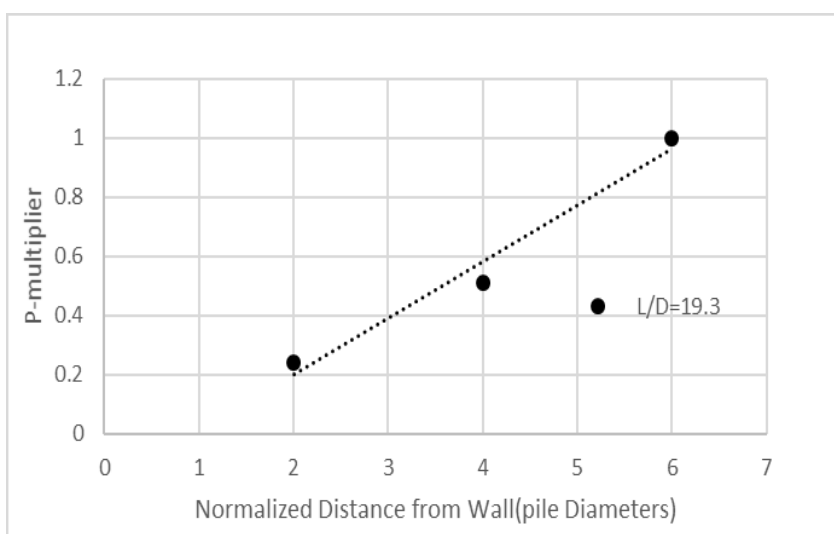

Figure 8: Tentative p-multiplier curve as a function of normalized distance (Nelson, 2013) 


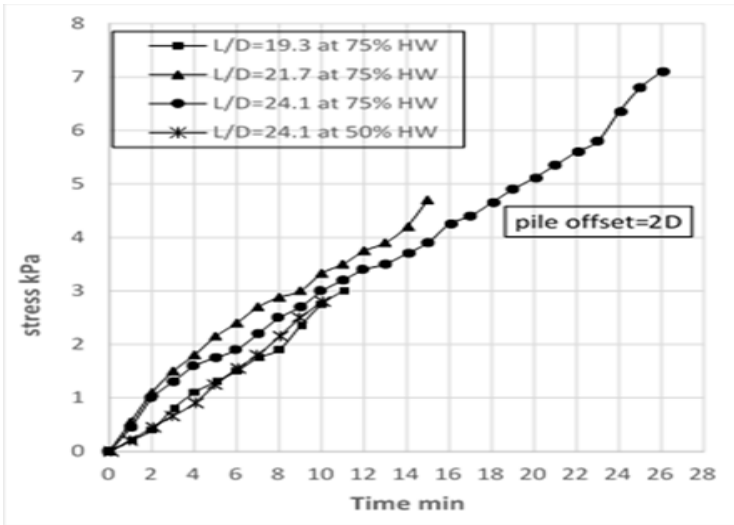

(a)

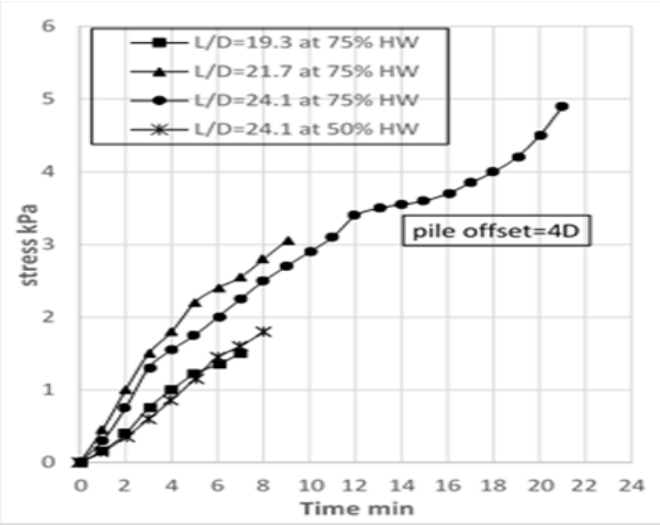

(b)

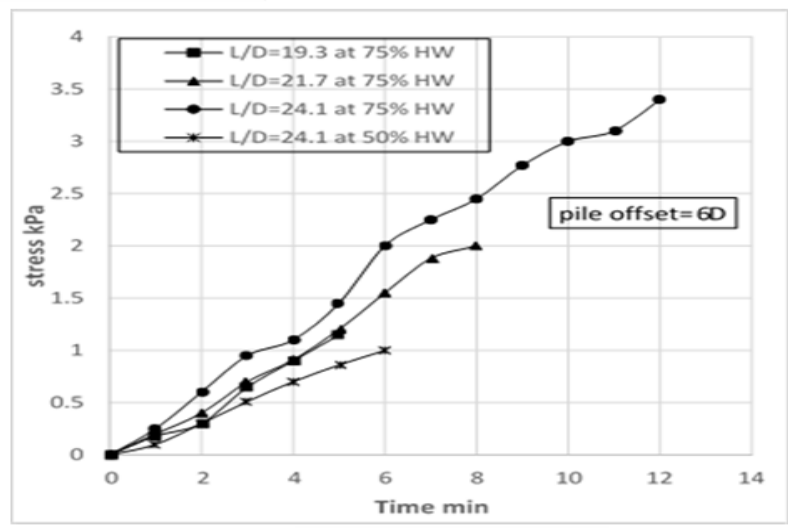

(c)

Figure 9: Stress-time curve of MSE wall in sand with relative density 50\%: (a) pile offset (2D); (b) pile offset (4D); and (c) pile offset (6D)

\subsection{Effect of pile offset and slenderness ratio on the pressure on MSE wall}

The ultimate pressures on MSE wall are determined from the stress-time curves. Figure 6(a), (b), and (c) illustrated the stress-time curves at offsets of pile of $41 \mathrm{~mm}(2 \mathrm{D}), 82 \mathrm{~mm}(4 \mathrm{D})$, and $123 \mathrm{~mm}(6 \mathrm{D})$, respectively.

The pressure sensors are located at two locations of the wall; at $50 \%$ and $75 \%$ of the height of the wall from the wall base. An increased in offset the pile decreased the pressure on the wall because of the increased distance between the pile and wall that leads to a decrease in the pressure on the wall. While an increase in the $\mathrm{L} / \mathrm{D}$ increased the pressure on the wall since increased the lateral pile deflection resistance in the soil when $\mathrm{L} / \mathrm{D}$ increased and as a result, the lateral earth pressure increased on the wall. For comparison purposes, the ultimate pressure on the wall for $\mathrm{L} / \mathrm{D}$ of 19.3 and pile offset of 2D is greater than the pressures on the wall when the offsets pile $4 \mathrm{D}$ and $6 \mathrm{D}$, respectively at the same $\mathrm{L} / \mathrm{D}$. Furthermore, the wall pressure increased with increasing the slenderness ratio (L/D) for the same the offset pile. There was the pressure high zone that formed at $75 \%$ of the height of the wall. This zone created from resistance of the soil to deflection of the laterally loaded pile. This soil at that location was compressed.

\section{Conclusions}

This study investigated the behavior of a pile subjected to lateral loading embedded with the MSE wall system considering the effect of various slenderness ratios (i.e., L/D) and different the offsets pile of (2D, 4D, and 6D) at a sand relative density of $50 \%$. The main conclusions drawn from the experimental work can be summarized as follows:

1) There is no actual design procedure within the MSE wall system for laterally loaded piles; more research is needed in this field.

2) An increase of the slenderness ratio (i.e., L/D) led to the pile increase the pile laterally capacity at the given relative density of sand $(50 \%)$.

3) The pile offset increase from the wall led to increase the pile laterally capacity. For a pile with L/D of 19.3 , increasing the offset pile to $6 \mathrm{D}$ increase ultimate of the lateral load to $51.4 \%$ and $24.7 \%$ in medium sand compared to those with pile offsets of $2 \mathrm{D}$ and $4 \mathrm{D}$, respectively.

4) An increased the offset pile decreased the pressure on an MSE wall; however, an increase in the slenderness ratio (i.e., L/D) increased the pressure on the MSE wall.

\section{Author Contribution}

All authors contributed equally to this work. 


\section{Funding}

This research received no specific grant from any funding agency in the public, commercial, or not-for-profit sectors.

\section{Data Availability Statement}

The data that support the findings of this study are available on request from the corresponding author.

\section{Conflicts of Interest}

The authors declare that there is no conflict of interest.

\section{References}

[1] R. E. Hamdi, M. Y. Fattah and M. F. Aswad, "Studying the settlement of backfill sandy soil behind retaining wall under dynamic loads," Engineering and Technology Journal, Vol. 38,Part A, No. 7, pp. 992-1000, 2020.

[2] V. Elias, B. R. Christopher, and R. R. Berg, "Mechanically stabilized earth walls and reinforced soil slopes design and construction guidelines," FHWA, Washington D.C., ReportFHWA-NHI-00-043,2001.

[3] W. K. Mohammed," Factors influencing performance of a laterally loaded pile within an MSE wall system,” M.Sc. thesis, CEAE, University of Kansas, Lawrence, USA, 2016.

[4] R.R. Berg, B.R. Christopher, and N.C. Samtani, "Design of mechanically stabilized earth walls and reinforced soil slopes," FHWA, Washington D.C., Report FHWA-NHI-10-024, 2009.

[5] M. C. Pierson, R.L. Parsons, J. Han, D.A. Brown, and W.R. Thompson, "Capacity of laterally loaded shafts constructed behind the face of a mechanically stabilized earth block wall," Kansas Department of Transportation, Lawrence, Kansas,Report K-TRAN: KU-07-6, 2009.

[6] K.R. Nelson, "Lateral resistance of piles near vertical MSE abutment walls at Provo Center Street," M.Sc. thesis, Department of Civil and Environmental Engineering, Brigham Young University, Provo, UT, USA, 2013.

[7] J. Han, "Lateral resistance of piles near 15 foot vertical MSE abutment walls reinforced with ribbed steel strips,"M.Sc. thesis, Department of Civil and Environmental Engineering, Brigham Young University,Provo, UT, USA,2014.

[8] K. Rollins, J. Price, and J. Bischoff, "Reduced lateral resistance of abutment piles near MSE walls based on full-scale tests," International Journal of Geotechnical Engineering, Vol. 6, No. 2, pp. 245-250, 2012.

[9] J. S. Price,"Lateral resistance of piles near vertical MSE abutment walls," M.Sc. thesis, Department of Civil and Environmental Engineering, Brigham Young University,Provo, UT, USA, 2012.

[10] American Society of Testing and Material (ASTM), "Standard Test Method for Particle Size- Analysis of Soils”, ASTM (D422-2001), West Conshohocken, Pennsylvania, USA, 2006.

[11] American Society of Testing and Material (ASTM), "Standard Test Method for Maximum Index Density and Unit Weight of Soils Using a Vibratory Table”, ASTM D4253-00, West Conshohocken, Pennsylvania, USA,2006.

[12] American Society of Testing and Material (ASTM), "Standard Test Method for Minimum Index Density and Unit Weight of Soils and Calculation of Relative Density”, ASTM D4254-00, West Conshohocken, Pennsylvania, USA, 2006. 